\title{
AVALIAÇÃO EPIDEMIOLÓGICA EM CÃES PORTADORES DE LINFOMA.
}

Osimar de Carvalho Sanches, Rogério Giuffrida, Liliane Giroto Pereira, Paula Keiko Anadão Tokawa, Vanessa Cristina Pereira

Medicina Veterinária- Universidade do Oeste Paulista - UNOESTE. E-mail: osimar@unoeste.br

\section{RESUMO}

O linfoma é denominado por uma proliferação neoplásica de linfócitos envolvendo órgãos linfóides sólidos. Pode ser classificada de alto, médio ou de baixo grau. Representando $90 \%$ das neoplasias do sistema hematopoiético nesta espécie, acomete com mais freqüência cães de raças de grande porte ou médio, como Boxer, Basset Hound, Rottweiler, Cocker Spaniel, São Bernardo, Golden Retriver, entre outros. O presente estudo tem como objetivo avaliar os dados quanto ao padrão racial, sexual e idade dos pacientes portadores de linfoma atendidos pelo serviço de patologia animal do hospital veterinário da Universidade do Oeste Paulista. Quanto ao padrão racial os animais sem raça definida (SRD), foram os que apresentaram maior incidência, já quanto ao sexo a maior ocorrência foi das fêmeas. Os cães idosos foram mais acometidos pelo linfoma. $O$ presente estudo faz parte de um projeto registrado com o № 1224 (CAPI).

Palavras-chave: Linfoma Canino, AgNOR, Proliferação

\section{1-INTRODUÇÃO}

O linfoma é uma neoplasia maligna de linfócitos que se caracteriza pela proliferação clonal de linfócitos, tendo como sítios iniciais os órgãos linfóides sólidos como baço, linfonodos, medula óssea e timo. Contudo, pode se desenvolver em praticamente qualquer órgão, pela contínua migração dos linfócitos pelos diferentes tecidos do organismo. Essa é a neoplasia hematopoiética mais freqüente em cães, correspondendo cerca de 5-10\% de todas neoplasias que acometem os cães (DOBSON e GORMAN, 1993; ANDRADE et al.,1994; CURIEL et al., 1998; VAIL, 2000; FIGUEIRA ET AL.,2002; VAIL \& YOUNG, 2007; DALECK ET AL., 2008).

Representa $90 \%$ das neoplasias do sistema hematopoiético nesta espécie (ROSENTHAL \& MACEWEN, 1990; OGILVIE \& MOORE, 1995). Acomete na maioria das vezes animais de meia-idade ou idosos, que perfazem $80 \%$ dos casos (GREENLEE ET AL., 1990; MOULTON \& HARVEY,1990), não havendo predileção sexual (VAIL \& OGILVIE,1998). Segundo SEQUEIRA et al (1999) as raças mais acometidas são especialmente raças de grande porte ou médio, como Boxer, Basset Hound, Rottweiler, Cocker Spaniel, São Bernardo, Golden Retriver, entre outros (NELSON \& COUTO,2006). Porém, a predisposição racial neste tipo de neoplasia ainda está em discussão. (MOULTON \& HARVEY, 1990) 
No Brasil são raros os levantamentos feitos sobre a incidência de linfoma em cães. (ANAI, 2011) A etiologia deste tipo de neoplasia é desconhecia. A presença de um componente viral ainda não foi comprovada na espécie canina (SEQUEIRA \& FRANCO,1992; TESKE, 1994 e SEQUEIRA et AL., 1999). Fatores ambientais, como exposição crônica a substancias químicas, são citados como predisponentes ao desenvolvimento de linfoma nos cães(HAYES et AL., 1991).

Anatomicamente, os linfomas caninos são classificados em 5 tipos: multicêntrico, digestivo, tímico, cutâneo e solitário, sendo a forma multicêntrica a mais freqüente (SEQUEIRA \& FRANCO, 1992; JACOBS et AL., 2002). Quanto a classificação cito-histomorfológica podem ser classificados como de alto, médio ou de baixo grau. E, quanto a imunofenotipagem, podem ser classificados como linfomas $T$, linfomas B, bem como mistos (B/T) (MUOLTON \&HARVEY, 1990; TESKE et AL., 1994; JONES et AL, 1997; DE MOURA et AL., 1999; SEQUEIRA et AL., 1999; VAIL, 2000, COLETA, 2009). Os Linfomas caninos são, na sua maioria originários de células B, sendo a menor parte de células T. (FIGHERA et al 2002).

Segundo a classificação da Oms (Organização Mundial de Saúde) os linfomas são classificados em estágios I,II,III,IV,V havendo diferença em quais os órgãos envolvidos e em substágios organizados em A e B onde A indica que o animal não apresenta sinais clínicos e B existem sinais clínicos. (FRADE et al 2008).

Segundo DERENZINI \& PLOTON,(1991), a característica mais marcante das céulas neoplásicas é também a maior expressão de AgNors que está relacionada única e diretamente com a proliferação celular.(DERENZINI\& PLOTON,1991; DERENZINI \& TRETÈ,1994). Para revelação das NORs pela prata, é necessário que as proteínas argirofílicas associem-se aos sítios de cromatina ribossômica, onde é inicializada a produção de grânulos ribossomais (DERENZINI \& PLOTON, 1991; PLOTON, 1994). As NORs são alças de DNA que ocorrem no nucléolo das células e possuem genes RNA ribossomais (DERENZINI et al., 1994).

A técnica de coloração de AgNors é altamente específica e pode ser utilizada em tecidos fixados em formol e embebidos em parafina, tecidos congelados, frescos ou de arquivo, esfregaços citológicos e preparados citocentrifugados (CROCKER,1992aㅡ)

\section{MATERIAIS E MÉTODOS}

\section{1) Origem das Amostras}

Foram avaliados 10 pacientes portadores de mastocitoma, contendo fragmentos da neoplasia, oriundas do arquivo do Serviço de Anatomia Patológica do Hospital Veterinário da 
Unoeste, colhidas no período de 2007 a 2011. O presente estudo está registrado na pósgraduação (CAPI) com o № 1224.

\section{RESULTADOS}

\subsection{Raças:}

Conforme o gráfico do presente estudo 40\%(4 animais) dos animais são considerados sem raça definida, as outras raças observadas apresentam 10\% (1 animal), sendo elas Lhasa Apso, Fox Paulistinha, Yorkshire Terrier, Boxer, Pity Bull, e Rottweiler.

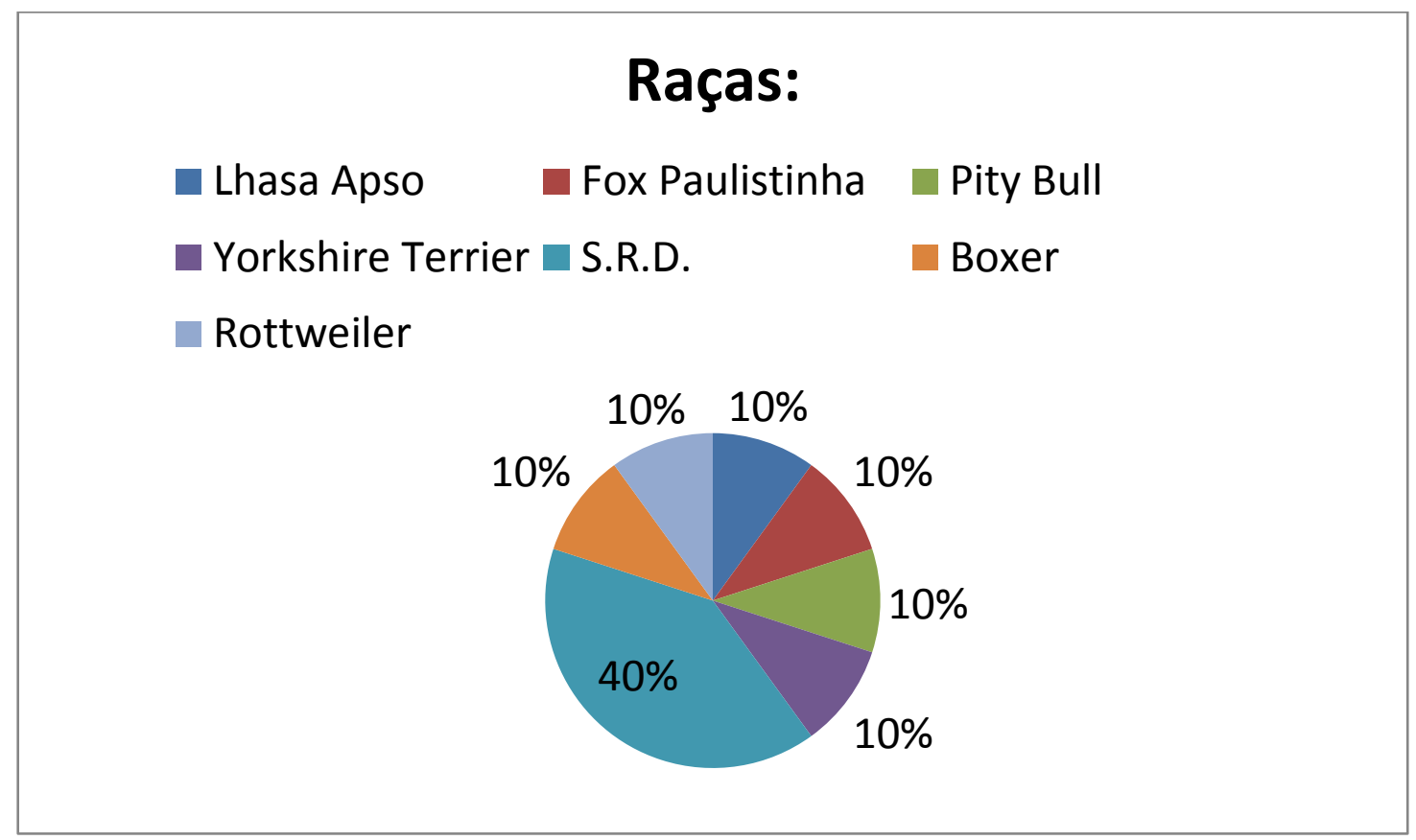

Figura 1. Raças dos 10 animais estudados

\subsection{Sexo:}

No presente estudo houve maior incidência de fêmeas acometidas 60\% (6 animais) sendo $40 \%$ de machos (4 animais).

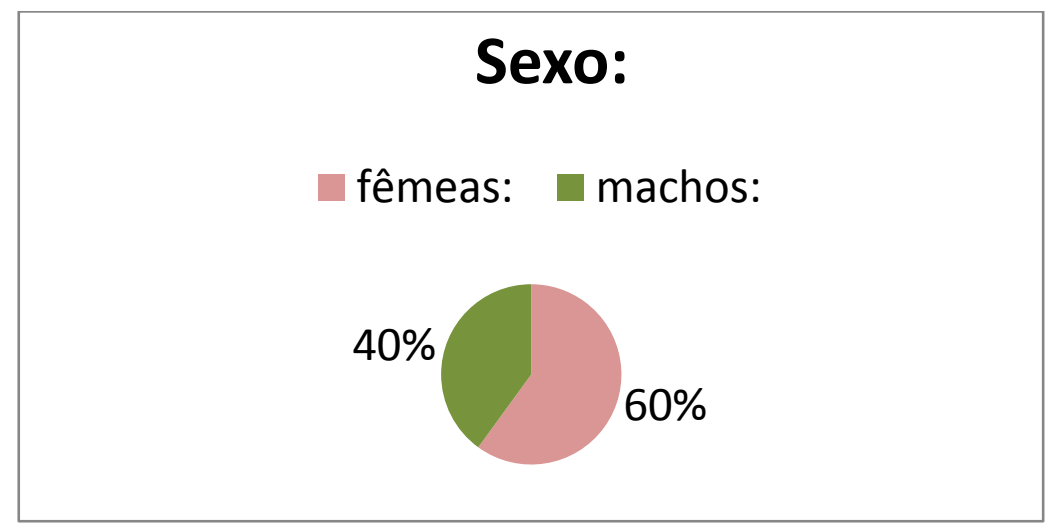

Figura 2. Sexo dos 10 animais estudados 


\subsection{Idade:}

Neste estudo pode-se observar que $50 \%$ dos animais (5 animais) são idosos, $30 \%$ (3 animais) adultos e 20\% ( 2 animais) adulto jovem, nenhum dos casos estudados apresentou acometimento em animais jovens.

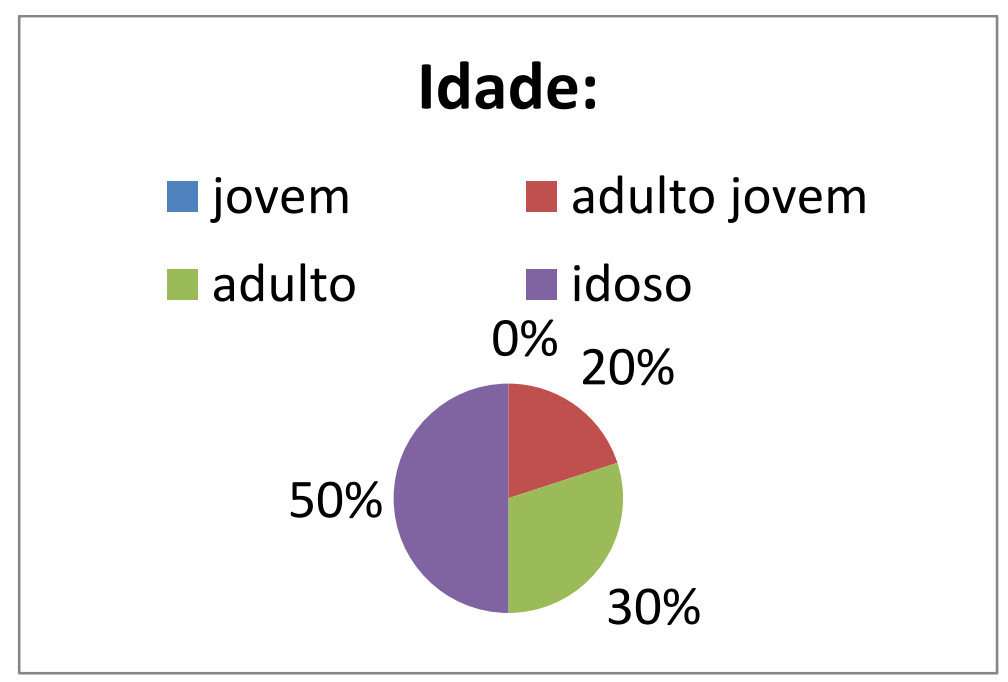

Figura 3. relação dos 10 casos do presente estudo

\section{DISCUSSÃO}

Em relação a raças alguns autores citam que as mais acometidas são de grande ou médio porte, como Boxer, Basset Hound e Rottweiler, pórem Moulton \& Harvey, (1990) cita que a predisposição racial ainda está em discussão, conforme o gráfico do presente estudo 40\%(4 animais) dos animais são considerados sem raça definida. Quanto a predileção sexual, segundo Vail \& Ogilvie (1998) não há predileção sexual,contudo no presente estudo houve maior incidência de fêmeas. Quanto a idade pode-se observar que $50 \%$ dos animais (5 animais) são idosos, não sendo diferente em alguns estudos indica que o linfoma acomete na maioria das vezes animais de meia-idade ou idosos, que perfazem $80 \%$ dos casos.

\section{REFERÊNCIAS}

ANAI, A.L. Evolução da expressão de CD45+ e do leucograma de cães linfomatosos durante quimioterapia com o protocolo de Madison-Wisconsin. . tese (doutorado em Medicina Veterinária)- faculdade de Ciências Agrárias e Veterinárias, Universidade Estadual Paulista, Jaboticabal, 2011. 
ANDRADE, A.L. NOVAIS, A.A.; LAUS, J.L.; ALESSI, A.C.; VSLERI, F.V.; CARVALHO, M.B. Manifestação ocular de linfoma maligno em cão. Ars Veterinaria, Jaboticabal, v.10, n.1, p.1-5, 1994.

CARDOSO, M.J.L. ET AL. Linfoma canino: revisão de cinqüenta e quarto casos.Bioscience Journal, Uberlandia, v.19,n. 3,p.131-142, 2003.

COLETA, F.E.D. Avaliação hematológica e imunofenotípica de cães com linfoma. 96f. tese (doutorado em Medicina Veterinaria)- faculdade de Ciências Agrárias e Veterinárias, Universidade Estadual Paulista, Jaboticabal, 2009.

CURIEL, J.M.A.S.; MCCAW, D.L.; TECK, M.A.M.; SCHMIDT, D.A. Multiple mucocutaneous lymphosarcoma in dog. Canadian Veterinary Journal, Ottawa, v.29, n.12, p.1001-1002, 1998

DALECK,C.R.;CALAZANS,S.G.;De NARDI,A.B. Linfomas.In:DALECK, C.R.; DE NARDI,A.B.;RODASKI, S. Oncologia em cães e gatos. São Paulo: Roca,2008p.481-505.

DE MOURA, V.M.B.D.; SEQUEIRA, J.L.; BANDARRA E.P. Linfoma canino.Revista de Educação continuada do CRMV-SP, São Paulo, v.2, n.2, p.29-33, 1999.

DOBSON, J.M.; GORMAN, N.T. Canine multicentric lymphoma 1: clinico-pathological presentation of the diseases. Journal of Small Animal Practice, London, v.34, n.12, p.594-598, 1993. http://dx.doi.org/10.1111/j.1748-5827.1993.tb02584.x

FIGUEIRA,R.A;SOUZA,T.M.;BARROS,C.S.L. Linfossarcoma em cães. Ciência Rural,Santa Maria,v.32,n.5,p.895-99,2002.

FRADE, C.S.; SILVA G.R.; BARROS P.M. Linfoma em pequenos animais. Universidade Castelo Branco, São José do Rio Preto, 2008.

GREENLEE,P.G. et al Lymphomas in dogs: a morphologic,immunologic,and clinical study. Cancer, Philadephia, v.66, n.5, p.480-490.

JONES, C.J., HUNT, R.D., KING, N.W. Veterinary pathology. 6 ed. Philadelphia: Willians \& Wilkins, 1997.

MOULTON,J.E.,HARVEY, J.W. Tumors of the lymphoid and hematopoietic tissues. In: MOULTON, J.E. Tumors in domestic animals. 3 ed. California :university of California, p.240-244,1990.

MORENO, K.; BRACARENSE, A.P.F.R.L. Estudo retrospectivo de linfoma canino no período de 19902004 na região do norte do Paraná.Brazilian Journal Veterinary Animal Science, São Paulo, v.44, p.46-52,2007.

NELSON, R.W.; COUTO, C.G. Medicina interna de pequenos animais.Rio de Janeiro: Elsevier, 2006. P.1087-1096.

OGILVIE, G.K.; MOORE, A.S. Management of Specific Diseases: Clinical Briefing: Lymphoma. In: Managing the veterinary cancer patient. Trenton: Veterinary Learning Systems, 1995. P.228-259. 
ROSENTHAL, C.R. MACEWEN, E.G. Treatment of lymphoma in dogs.Journal of the American Veterinary Medical Association,Schaumburg,v.196 n.5,p. 774-781, 1990.

SEQUEIRA, J.L.;FRANCO, M. ; BANDARRA, E.P.; FIGUEIREDO, L.M.A.; ROCHA, N.S. Características anatomoclinicas dos linfomas caninos na região de Botucatu/SP. Arq. Bras. Med. Vet. Zootec., Belo Horizonte, v.51, n.3, p.245-249, 1999.

SEQUEIRA, J.L., FRANCO, M., BANDARRA, E.P. ET AL. Caracteristicas anatoclínicas dos linfomas caninos na região de Botucatu, São Paulo.Arquivo Brasileiro De Medicina Veterinária e Zootecnia, Belo Horizonte, v.51, n.3, p.1-11, 1999.

SEQUEIRA, J.L.; FRANCO,M. Características dos linfomas caninos. J. anatomopatol.,Ribeirão Preto,v.7,n.2, p.6-8, 1992.

TESKE, E. et al. Prognostic factors for treatment of malignant lymphoma in dogs. Journal of the American Veterinary Radiology \& Ultrasound, Raleigh, v.38, n.6, p.411-418,1997.

TESKE, E. Canine malignant lymphoma: a review and comparison with human non-Hodking's lymphoma.Vet Quart, 1994c(16); 4:209-219. http://dx.doi.org/10.1080/01652176.1994.9694451

VAIL, D.M. Hematopoietic tumors. In: ETTINGER, S.J.;FELDMAN, E.C.

Textbook of veterinary internal medicine. Philadelphia: Saunders, 2000. p.507-522.

VAIL,D.M.;YOUNG,K.M. Hematopoietic tumors.In: WITHROW,S.J.;VAIL,D.M. Small animal clinical oncology. 4 ed.Missouri:Saunders,2007.p.699-784.

VAIL, D.M.; OGILVIE, G.K. Neoplasias Linfóides. In:BICHARD, S.J.; SHERDING, R. G. Manual saunders-clinica de pequenos animais.São Paulo: Roca, 1998. Cap.6 p.218-225.

VALLI, V.E., SAN MYINT, M., BARTHEL, et al. Classification of Canine Malignant Lymphomas According to the World Health Organization Criteria; 2010 